\title{
Gestão municipal da educação, organização do sistema nacional e regime de colaboração: algumas questões
}

\section{Municipal education management, organization of the national system and collaboration regime: some questions}

\author{
Tais Moura Tavares* \\ A maioria dos problemas de administração pública \\ reclama, para a boa solução, \\ ação conjunta das várias órbitas de poderes: \\ a municipal, a estadual e a federal. \\ E se tais problemas chegam a envolver \\ ação de cunho predominantemente social, \\ como a da economia, a da educação e a da saúde, \\ esse espírito de boa colaboração se torna, \\ então, de todo imprescindivel. \\ Lourenço Filho
}

\section{RESUMO}

Apesar da ambigüidade adquirida pelo termo "público", partimos do pressuposto de que a educação é tarefa social sob responsabilidade do Estado. $\mathrm{O}$ federalismo brasileiro reparte o atendimento à educação nas diversas instâncias federativas. A ausência da efetivação do regime de cooperação e colaboração, apesar da existência de preceitos legais que a exigiriam, acentuou a fragmentação das políticas educacionais e a não constituição de um sistema

* Professora do Departamento de Planejamento e Administração Escolar, do Setor de Educação da Universidade Federal do Paraná. E-mail: 
nacional de educação. A municipalização do ensino fundamental tem sido instrumento de descentralização e tem reforçado a atomização das ações pedagógicas. Por outro lado, férteis experiências no âmbito da gestão municipal têm apresentado alternativas democráticas, particularmente no que se refere à gestão educacional.

Palavras-chave: política educacional, sistemas de educação, regime de colaboração.

\begin{abstract}
In spite of the acquired ambiguity of the term "public", we broke of the presupposition that the education is social task under responsibility of the State. The Brazilian federalism distributes the service to the education in the several federal instances. The absence of execution of the cooperation regime and collaboration, in spite of the existence of legal precepts that were necessary, accentuated the fragmentation of the education politics and the non-constitution of a national system of education. The "municipalização" (kind of decentralization to the counties based on municipal management) of the fundamental teaching has been an instrument to reinforce the atomization of the pedagogic actions. On the other hand, fertile experiences in the extent of the municipal administration have presented democratic alternatives, particularly in which is referred to the education administration.

Key-words: education politics, education systems, regime of collaboration.
\end{abstract}

\title{
O poder público e o sistema nacional de educação
}

Como atividade humana, a educação não diz respeito apenas a cada indivíduo. A capacidade de ser humano - a humanidade - é questão social e, por ser social, é questão pública. E como questão pública deve ser coletivamente organizada e é isto que está em discussão quando tratamos da organização do sistema da educação nacional.

O conceito de público tem sido um dos mais controversos ultimamente. Vivemos um período em que mudamos o público de lugar. Por longo tempo entendemos que quem deveria manter e zelar pelo atendimen- 
to de atividades de interesse público era o Estado. Na década de 90, entretanto, nos acostumamos a ouvir um discurso que afirmava que o público era de responsabilidade da sociedade, em nome do respeito à diversidade dos grupos sociais e em nome do desejo e da necessidade da participação.

Ora, nós não vivemos numa sociedade onde existem apenas diferenças. Vivemos numa sociedade marcada por desigualdades. Vivemos numa sociedade em que não há garantia de participação econômica, social, política e cultural para todos. A localização das políticas de atendimento aos direitos sociais no plano da sociedade é a definição dessas políticas no lócus da desigualdade - cada comunidade, grupo, entidade etc. oferece o atendimento dentro das condições que possui, com maior ou menor grau de universalização e qualidade dependendo dos recursos disponíveis. O papel equalizador das desigualdades exercido pelo Estado, pelo que chamamos poder público, vai sendo minimizado, a manutenção precarizada e a privatização acentuada.

Consideramos, a partir dessa reflexão, que pensar a organização da educação requer a afirmação de dois princípios fundamentais. Primeiro, o entendimento de que a educação, enquanto direito de cidadania e bem social, é de responsabilidade do poder público e que cabe à sociedade exercer fiscalização sobre a oferta pública de educação em todos os seus níveis e modalidades. Segundo, a direção da política educacional levada pelo Estado tem que tomar a direção da garantia da igualdade (de condições e de oportunidades) e de efetiva democratização. A partir desses princípios é possível refletir sobre qual forma de organização da educação propicia a realização da democratização educacional.

Atualmente, o atendimento educacional é feito pelo poder público em todas as suas instâncias federativas: a União, os estados e os municípios. As instituições privadas integram os respectivos sistemas de ensino.

Alguns fatos devem ser considerados. Apesar de termos todas essas instâncias oferecendo ensino de diversos níveis e modalidades, o nosso atendimento educacional é muito precário. Temos uma dívida histórica. Ainda permanece o analfabetismo, nem todas as crianças de 7 a 14 anos estão na escola, o atendimento da Educação Infantil é baixíssimo, o do Ensino Médio não chega nem na metade dos jovens em idade própria, nem temos estatísticas suficientes de quantos alunos deveríamos atender na Educação Especial, o atendimento no Ensino Superior é principalmente privado. Convivemos ainda com altos índices de reprovação e evasão, tanto 
por causas extras como intra-escolares. Os salários dos profissionais da educação são baixos, as condições materiais e físicas das escolas deixam a desejar.

Desde a década de 70, há estudos clássicos que apontam a inexistência de um sistema nacional de educação. A luta travada pelo projeto da Lei de Diretrizes e Bases buscou equacionar este problema secular. As análises posteriores à promulgação da Lei apontaram que a Lei 9394/96 substituiu a idéia de um sistema nacional de educação pela idéia de um sistema nacional de avaliação.

Não existe sistema nacional porque não garantimos no conjunto das escolas, níveis, modalidades, unidade na diversidade. A diversidade tem resultado, entre nós, em fragmentação, sobreposição de instâncias, excessivo controle burocrático em certos aspectos, total falta de acompanhamento em outros. O poder federal estabeleceu, por exemplo, um sistema de avaliação de caráter nacional sem discussão com nenhuma instância e, ao mesmo tempo, não cumpriu a função redistributiva de fazer a complementação dos recursos do Fundef. Descentralizou a oferta da educação básica, mas manteve seus próprios projetos de presença junto aos municípios e as unidades escolares, como a Alfabetização Solidária ou o Dinheiro Direto da Escola. Os estados municipalizaram a primeira fase do Ensino Fundamental em nome do cumprimento da LDB, mas boa parte das suas escolas têm necessidades de manutenção supridas pelos municípios. Ao mesmo tempo, estes mantêm direta ou indiretamente instituições de Ensino Superior quando ainda não garantiram a ampliação necessária de oferta na Educação Infantil.

Uma palavra própria deve ser dita a respeito dos municípios. Os analistas afirmam que a Constituição de 88 foi uma constituição municipalista, dado que reconheceu o município como ente federativo, em pé de igualdade com os estados. O movimento que se seguiu foi de progressiva descentralização da execução das políticas sociais - saúde, educação, habitação, saneamento etc.- para os municípios. Em nome da autonomia, estados, municípios e escolas passaram a assumir responsabilidades ampliadas, embora dificilmente tenham participado das definições das políticas.

A descentralização progressiva do atendimento educacional para os municípios tem levado ao risco do localismo, ou seja, ao fechamento das proposições e das possibilidades às condições singulares de cada município. Cada um fica entregue às próprias condições de pobreza e/ou riqueza, distanciando-se o horizonte da igualdade e, afirmando-se insistentemente a 
desigualdade como princípio. Ao mesmo tempo, fica o município e as escolas sujeitos à ingerência tanto do governo federal quanto estadual, quando algum projeto lhes interessa.

A partir das idéias de autonomia e descentralização, muitíssimo em voga tanto nos campos de esquerda quanto no âmbito das políticas neoliberais, pode-se chegar a acentuado grau de fragmentação das políticas educacionais. De um momento próprio ao autoritarismo da década de 70, em que houve considerável centralização das decisões no âmbito do executivo federal, seguiu-se, na década de 80, uma ênfase na democratização da gestão da educação, com o processo de democratização social e político do país, em que se privilegiou a autonomia, resultando, como uma das conseqüências, no fortalecimento do movimento municipalista.

A Constituição de 88, ao dar estatuto de ente federativo aos municípios, consolidou a linha municipalista que ensejou, posteriormente, o processo de descentralização e municipalização das políticas sociais foi levado a termo pelos governos federais na década de 90 .

Embora no âmbito da educação tenha permanecido certa dubiedade na Constituição de 1988, dado que se fala de sistemas municipais, mas só se atribui aos estados e à União a competência legislativa, a Lei 9394/96 vai corrigir esta ambigüidade ao declarar explicitamente a possibilidade da criação de sistemas municipais de ensino.

A perda da perspectiva da criação do sistema nacional de educação não resultou em lutas específicas nesta direção. Os movimentos organizados e a produção acadêmica voltaram seus esforços à implementação de políticas progressistas de educação, no âmbito dos municípios conquistados pela oposição e na democratização da gestão dos estabelecimentos de ensino. Paradoxalmente, dois movimentos distintos - o da política federal e dos movimentos sociais na educação - convergem para uma mesma priorização do local e da unidade escolar.

Podemos explicar esta convergência se considerarmos que, por um lado, há uma Reforma do Estado na qual a descentralização é uma forma de resolver a crise fiscal, porque acaba resultando num processo de sustentação financeira dos serviços pelos próprios cidadãos. De outro lado, na impossibilidade de intervenções significativas no plano federal, os movimentos voltam-se a espaços mais possíveis de intervenção política: os municípios e as escolas.

Com esta argumentação, queremos afirmar que há uma secundarização da idéia de sistema de ensino e sua restrição a constituição no âmbito dos 
municípios. Podemos dizer que esta idéia vai assumindo progressivamente um caráter localista.

\section{Centralização e descentralização na organização do sistema de ensino no Brasil: um pouco de história}

A discussão da gestão municipal da educação tem origem em diversas vertentes de análise, tanto à direita quanto à esquerda do espectro político. A descentralização do ensino para os níveis subnacionais tem ocorrido na América Latina, tanto em governos democráticos quanto em ditaduras militares, e aparece como recomendação dos organismos internacionais como a Unesco, a OEA, o BIRD e o BID etc.

No Brasil, a proposição de responsabilizar o município pelo Ensino Fundamental e pela Educação Infantil está presente já na legislação educacional do período militar e criou fôlego com os programas que se implementaram na década de 80 e, principalmente de 90, o que nos leva a dizer que esta responsabilização é uma das linhas principais das políticas educacionais das últimas décadas. O exame dos dados estatísticos mais recentes dá idéia da progressiva e irreversível municipalização das matrículas.

A municipalização, ou seja, a descentralização do ensino foi estratégia já configurada no bojo da Lei 5692/71 como desresponsabilização com a expansão e democratização do ensino num contexto concentrador, tal como apontado por Arelaro:

... a descentralização é a expressão de que os detentores do poder não estão seriamente empenhados no compromisso democrático educacional. Se estivessem, teriam, coerentemente, proposto - como fizeram nas áreas que lhes interessavam - uma mudança radical, uma lei basicamente centralizadora. (ARELARO, 1980, p. 196) 
Se analisarmos a história do sistema de ensino no Brasil, vamos verificar que a descentralização foi uma das formas de concentrar a atenção na educação das elites.

Tem sido frequente a afirmação de que os serviços educacionais devem ser ou já estão sendo descentralizados por meio da transferência de responsabilidades entre os níveis de governo, do plano federal e estadual para o municipal. Esta afirmação parte da suposição de que esses serviços estiveram até o momento sob responsabilidade do governo central, que definiu políticas, esferas de execução e exerceu controle sobre as formas e resultados das ações.

Segundo Sofia Lerche Vieira, é senso comum da história da educação brasileira situar a gênese da descentralização da educação na promulgação do Ato Adicional de 1834. Segundo a autora, esta origem remonta a 1828, na lei que atribuiu às câmaras municipais competências no campo educacional, tais como inspeção sobre as escolas de primeiras letras, e educação e destinos dos órfãos e auxílio aos estabelecimentos escolares e de caridade mantidos por outras autoridades (VIEIRA, 2000, p. 28).

Esta afirmação poderia levar à conclusão de que a gestão da educação, como tendência, é descentralizada desde as suas origens. Entretanto, Vieira aponta a marca centralizadora no período colonial, contra a qual existiram movimentos de insurgência: "se a centralização é a tendência dominante das origens de nossa história, um movimento na direção contrária também se expressa como tendência dominada no cenário que vai se configurando na sociedade emergente. (VIEIRA, 2000, p. 29)

Há, portanto, desde os primórdios da educação brasileira, um duplo movimento de centralização/descentralização, que relativiza a classificação da política educacional de um dado período dentro de uma só direção.

No período 1998-1930 há um movimento pendular: ora prevalece um dos movimentos, ora outro, nas reformas de ensino realizadas no período: Reforma Epitácio Pessoa (1901), prevalece a centralização; Reforma Rivadávia Corrêa (1925), a descentralização; Reforma Carlos Maximiliano (1915) e João Luís Alves (1925), afirmam a centralização. Cabe lembrar que essas reformas não têm alcance de âmbito nacional e que a década de 20 é fértil em proposições políticas de reformas educacionais de âmbito estadual, o que afirma a tese de descentralização e talvez explique a permanência, na atualidade, de uma dominante oferta do Ensino Fundamental, localizada nas redes estaduais. É esta a posição presente no Movimento dos Pioneiros, em 1932. 
A tese centralizadora se reafirma nas reformas a partir de 30, gestadas num período autoritário, no qual se formulam medidas centralizadoras para outros âmbitos da política nacional: a Reforma Francisco Campos (19311932) e as Leis Orgânicas do Ensino (1942-1946). (ROMANELLI, 1978) Entretanto, só a reforma do Ensino Primário, de 1946, é que vai alterar a Educação Básica, até então administrada e regulamentada por iniciativas de âmbito estadual e/ou municipal.

Ou seja, mesmo as reformas centralizadoras conviveram com um amplo espaço de atuação dos estados e municípios na responsabilidade sobre a faixa da educação escolar a qual têm acesso (ou deveriam ter) as massas populares. As reformas anteriores tiveram como objeto principal as etapas da educação que atende ou às elites, como é o caso do Ensino Superior, ou os centros urbanos em processo de industrialização, como o ensino técnico e profissional. A educação das massas ficou relegada às possibilidades, condições e vontade política existentes nos planos de governo subnacionais.

Os dilemas que marcam a discussão da Lei ${ }^{\circ} 4.024 / 61$ acerca da centralização/descentralização envolve uma disputa de poder entre regiões do país economicamente e politicamente fortes no cenário nacional, num contexto onde estados e municípios já vinham de fato se responsabilizando pelo ensino fundamental. Segundo VERAS, citada por VIEIRA (2000, p. 30), o que estava em questão nesta discussão era a partilha de responsabilidades entre a União e as unidades federadas, o que não explica em que medida o dilema não se punha por sobre uma situação já instituída e não alterada de fato (apesar das iniciativas de âmbito legal e político) de responsabilidade dos estados e municípios pela Educação Básica.

A Constituição de 1967 mantém a organização de sistemas de ensino como competência da União e das unidades federadas e que a Lei n. 5.692/ 71 aponta para a progressiva responsabilidade dos municípios na manutenção e oferta do Ensino de $1^{\circ}$ Grau. Se tomamos a referência do contexto histórico, observamos que este é um período de extrema centralização política.

Podemos afirmar que a descentralização é uma dos temas centrais da política educacional nas duas últimas décadas. Como vimos, há um histórico anterior de responsabilização dos poderes subnacionais pela educação básica. Entretanto, o período da ditadura militar esteve marcado pela centralização autoritária e tecnocrática, como é exemplo a legislação educacio- 
nal, o que resulta na importância de medidas descentralizadoras que aparecem como reação ao período autoritário. Levamos ainda em consideração que a política educacional mais recente têm suas origens no que se delineou a partir de 1985 .

Para análise da descentralização no período 1985-1995, baseamo-nos no estudo de Sofia Lerche Vieira sobre a política educacional nos governos Sarney (1985-1990), Collor (1991-1992), Itamar (1993-1994) e primeiro ano de governo de Fernando H. Cardoso (1995) (VIEIRA, 2000). Neste estudo, a descentralização aparece, juntamente com a qualidade, como grande tema do período 1985-1995, tomando-se como foco central o papel da União como formuladora de políticas. Sua presença é constada em todos os documentos analisados, tornando-se marcante no desenrolar das administrações federais, de modo a ir se explicitando como uma das estratégias centrais de modernização da gestão pública e reforma do Estado.

Embora a centralidade do estudo se situe na análise de documentos expressivos do planejamento estatal, os dados estatísticos sobre o ensino básico no período 1985-1996 confirmam: 1 - o decréscimo de participação federal no atendimento, quer do Ensino Básico, quer do Superior; a presença estadual na oferta de Educação Básica (crescente em relação ao Ensino Médio); a progressiva, mesmo que lenta, municipalização da Educação Infantil, do Ensino Fundamental e também do Ensino Médio. O que os dados demonstram é que para além de uma estratégia anunciada, a descentralização se configura como uma ação que se efetiva em termos das políticas de educação, iniciando-se com transferência de responsabilidades e execução de programas complementares, como o da merenda escolar, mas atingindo efetivamente o plano do atendimento da demanda de educação básica.

No planejamento público, a idéia da descentralização surge como crítica de centralização existente nos governos Sarney e Collor, efetiva-se como estratégia na condução descentralizada do Plano Decenal de Educação e no descentralização do Programa de Merenda Escolar para assumir, já no primeiro ano do governo F.H.C., a forma de um conjunto de ações voltadas não só a um reordenamento entre as esferas federal, estadual e municipal, mas também e principalmente tomando a escola como foco de atuação prioritária.

Deve-se destacar neste último período a forma centralizada com que a descentralização é definida e efetivada. Em que pese a vinculação, no plano da intenção e das idéias, entre descentralização e participação, a partir 
de 1995, a descentralização vem de dentro na medida em que o MEC retoma o papel de formulador e emanador das políticas da educação. Segundo a autora, o governo federal toma as rédeas da política educacional." (VIEIRA, 2000, p. 218)

\section{A municipalização do ensino como estratégia de descentralização}

A política de municipalização insere-se no movimento de descentralização resultante das modificações econômicas, sociais e políticas presentes no contexto da globalização. As modificações no plano da estrutura de poder afetam, como não poderia deixar de ser, o funcionamento dos sistemas educacionais. Há uma adequação da rede pública às tendências gerais do capitalismo contemporâneo no que se refere, especialmente, à reorganização das funções administrativas e gestão da escola e processo de trabalho dos professores.

Um dos elementos que marcam esta reorganização é a descentralização administrativa e operacional, levando as escolas a se adaptarem às condições locais municipais e os sujeitos envolvidos no processo educacional, a uma maior responsabilização no interior da escola. Ao MEC e Secretrarias de Educação cabe o controle sobre a distribuição de recursos, dos meios de acompanhamento e de avaliação de resultados. (BRUNO, 1997)

Segundo Romualdo Oliveira, na ótica do BIRD, a municipalização configura-se como uma estratégia de racionalização, de combate de desperdício de recursos. Há, no processo aqui instaurado, uma transferência de encargos de uma esfera pública a outra, "o que não significa necessariamente democratização" (In OLIVEIRA, 1997).

ROSAR (1995) também aponta a redução de recursos federais aplicados no Ensino Fundamental, assim como a estratégia dos governos estaduais em desonerar-se desta etapa da Educação Básica, passando os encargos aos municípios, configurando o processo de municipalização dentro das políticas de cunho neoliberal.

Como a direção do processo descentralizador não é a da democratização do poder, pode-se afirmar que há um deslocamento de um plano de autoritarismo na gestão educacional para outro plano de gestão - o munici- 
pal - onde as relações de poder não são necessariamente mais democráticas. A municipalização não põe em questão as relações de poder existentes no plano local municipal, diluindo diferenças e possibilidades de oposição entre projetos de caráter genericamente democrático e aqueles voltados apenas a uma descentralização de execução de políticas.

A autora faz o contraponto entre as políticas de descentralização como a da municipalização com os resultados da vigência de modelos centralizados na América Latina:

A decisão de se adotar a descentralização como alternativa metodológica e política para os problemas educacionais nos países da América Latina, América Central e Caribe obscurecem os resultados positivos da política educional do Estado centralizado que permitiu a incorporação massiva da população aos serviços educacionais. (ROSAR, 1995, p. 49)

As relações clientelísticas que marcam fortemente o plano de poder local, bem como a fragilidade das instâncias representativas dos interesses da maioria da população e a força de expressão dos interesses das elites locais sobre a opinião pública determinam as dificulades e limites de um processo efetivo de democratização do ensino no plano municipal, mais contundente de considerarmos a amplitude da responsabilidade educacional do município, desde a Educação Infantil, Ensino Fundamental, chegando à Educação de Jovens e Adultos, áreas de extrema carência e déficit de atendimento. (ARELARO, 1989)

A Lei n. 9424/96, que criou o Fundef, é restritiva da autonomia municipal na medida em que o município perdeu o controle sobre os seus próprios recursos. As condições existentes nos municípios e a vontade política da população não foram considerados no processo que impeliu à municipalização. (PAVAN, 1998) 


\section{Projetos alternativos de educação básica no âmbito da gestão municipal: possibilidades e limites}

Em que pese a direção neoliberal presente na política de descentralização e municipalização, tem ocorrido, no âmbito de municípios brasileiros, a adoção de políticas de cunho democrático, desde o início da década de 90, como são exemplos a Escola Pública Popular de São Paulo, a Escola Plural de Belo Horizonte, a Escola Cidadã de Porto Alegre. Ao longo da década, um conjunto significativo de outras experiências se juntaram a essas, espalhadas em todo o território nacional.

Esses municípios vêm constinuindo sistemas próprios de ensino como forma de resistência à imposição das políticas de cunho neoliberal implementadas até 2002 pelo governo federal e pela maioria dos governos estaduais. Ou seja, não garantidas na LDB as proposições que assegurariam no plano nacional um projeto democrático de educação, as forças progressistas tiveram, no âmbito municipal, a possibilidade de enfrentamento e construção de resistência ao desmonte da escola pública.

Segundo PONTUAL (2000), no final da década de 80, inicia-se um número significativo de mandatos de prefeitos eleitos por coligações progressistas. Esses mandatos passaram a apontar a possibilidade de o poder local se constituir em laboratório de projetos inovadores, de estímulo à participação popular na definição do rumo das políticas públicas. Daí aparecem experiências como da Consituinte Escolar, Orçamento Participativo, Ciclos de Formação Humana, Conferências Municipais de Educação etc. Esses municípios desenvolveram políticas públicas próprias de ampliação do atendimento à Educação Infantil, a oferta pública de Educação de Jovens e Adultos, estratégias de enfrentamento dos problemas de evasão e repetência, formas de assegurar a inclusão da educação espacial no espaço do ensino regular.

As experiências mais significativas dizem respeito à gestão educacional. As definições das prioridades em termos de ação governamental passaram a ser feitas em instâncias de participação popular. União da Vitória, por exemplo, definiu o plano de trabalho da gestão a partir de Conferências Municipais de Educação, da qual participaram todos os educadores da rede de ensino, do Ensino Fundamental e Educação Infantil, bem como representantes de outros setores do município. A implementação das ações su- 
pôs a presença permente de grupos de trabalho e espaços de discussão que contribuiram na elaboração e exerceram controle sobre o poder público.

Outros municípios vêm trabalhando na elaboração dos planos municipais de educação e na constituição dos Conselhos Municipais de Educação. O foco principal tem sido o de superar a concentração de poder no executivo municipal - as secretarias de educação - ampliando a possibilidade de participação da mais ampla parte possível dos sujeitos sociais que fazem parte da municipalidade. Há a busca de que as representações superem o limite do corporativismo na direção de representações permeadas de um sentido mais geral e mais público. Neste sentido, por exemplo, experiências em curso tentam definir como conselheiros para o Conselho Municipal de Educação aqueles escolhidos pelos movimentos organizados, que não sejam necessariamente pessoas da categoria, mas aquelas que, independentemente disso, representem o projeto de educação que se quer para o município.

Da mesma forma, a elaboração do Plano Municipal de Educação deve ser fruto do mais amplo debate social, buscando abarcar a participação dos setores tradionalmente organizados em sindicatos, associações etc. mas, além desses, os setores "ainda desorganizados", que convivem em espaços não-qualificados como políticos, como por exemplo, as igrejas.

Entretanto, pesquisas apontam os limites de administração municipal na falta de articulação com os demais níveis de governo co-responsáveis pela Educação Básica. (PAVAN, 1998). Corre-se o risco de comprometer o processo de democratização dado que a política de educação para o município como um todo pode ficar fragmentada entre uma política para as escolas municipais e outra para as escolas estaduais existentes num mesmo município, reforçando as rupturas ainda existentes entre as diversas etapas da educação básica:

A municipalização do ensino, em maior ou menor escala, atualiza a necessidade de se repensar a concepção de sistema e a distinção entre único e unitário. Único remete à idéia de "que é só um, enquanto unidade remete à idéia de "coordenação, organização das partes", "ação coletiva tendente a um fim único". Dessa forma, pensar a unidade do sistema público não deve significar a existência de um único órgão de gestão (...) A unidade do sistema comporta o múlitplo, o heterogêneo, desde que seja coordenado, articulado (...), pois visa a um fim único, no caso a igualdade no ponto de chegada. (PAVAN, 1998, p. 125) 


\section{O regime de colaboração}

Diante da desorganização e fragmentação da educação nacional, precisamos afirmar alguns horizontes de sua possível organização e construção de um sistema nacional unitário. Em primeiro lugar, precisamos definir o que, quanto e como deve ser centralizado e descentralizado para que a democratização da educação se efetive. Não há centralização de um lado e, de outro, descentralização. A prática tem sido de centralização das decisões e descentralização da manutenção e da responsabilidade pela execução. Este é o modelo que temos conhecido e que resulta de decisões tomadas tecnocraticamente, desconhecedoras da realidade concreta, que muitas vezes atrapalham e entravam o cotidiano da prática pedagógica. Quem faz tem que participar das decisões.

Em segundo lugar, descentralizar poder não pode ser encerrar a esfera de poder em âmbitos reduzidos que solitariamente não detém a capacidade das grandes definições de ordem econômica, política e social. Não se define no âmbito do município a política cambial, a resolução do problema do pleno emprego, a migração da miséria, o preço do petróleo, a intervenção das agências financiadoras internacionais, o desequilíbrio ecológico planetário, o crescimento da violência, por exemplo. O poder de cada parte está determinado pela articulação do conjunto e parece um paradoxo afirmar, ao mesmo tempo, a globalização e a autonomia do município para resolução de problemas de ordem macrosocial.

No âmbito das políticas sociais, e particularmente na educação, há de se fazer valer o que está na Constituição de 1988, na LDB e na Lei do Plano Nacional de Educação: o regime de colaboração. Nos capítulos da legislação, que determinam as respectivas competências em matéria de educação, afirma-se e reafirma-se o regime de colaboração. Considerando que convivemos e conviveremos com grande diversidade no ponto de partida, cuja reificação manterá a desigualdade como princípio, devemos organizar as formas de colaboração que permitam a progressiva unidade da diversidade dentro da qual serão asseguradas as mesmas condições e oportunidades de acesso e freqüência à escola.

Além disso, carecemos de um debate nacional sobre o conteúdo da educação na contemporaneidade. A LDB definiu a base comum nacional do currículo. A parte complementar cabe aos sistemas e/ou estabelecimentos 
de ensino. Os Parâmetros Curriculares Nacionais, ao serem impostos como a referência para os exames nacionais, abortaram a possibilidade de um profícuo debate nacional. O desenho curricular supõe um leque de escolhas que não podem ser feitas por um pequeno grupo, na medida em que é questão coletiva e pública.

Do mesmo modo, como condição primordial da efetivação do direito à educação, precisamos chegar a patamares comuns de condições de salário e trabalho dos profissionais da educação. Precisamos definir conjuntamente quais são os indicadores de padrão de qualidade do ensino, indicado mas não estabelecido pela LDB.

Todas essas são considerações que têm que ser levadas em conta no momento em que um município, enquanto sujeito político, se propõe a organizar seu sistema próprio de ensino, seu conselho e seu plano municipal de educação. Ou seja, esta organização vai ter efetivo sentido democrático, social e educacionalmente, se se colocar no horizonte da construção de um sistema nacional de educação. Qual das possibilidades - integrar-se ao sistema estadual ou constituir-se em sistema próprio - aproxima-se mais, consideradas as condições históricas de um projeto educacional efetivamente popular e democrático?

\section{REFERÊNCIAS}

ARELARO, L. R. G. A descentralização na Lei 5692/71: coerência ou contradição. São Paulo, 1980. Dissertação (Mestrado) - Faculdade de Educação - USP.

. A municipalização do ensino e o poder local. Ande, São Paulo, n. 14, p. 22-26, 1989. [c/autor: é revista mesmo?]

BRUNO, L. Poder e administração no capitalismo contemporâneo. In: OLIVEIRA, D. A. Gestão democrática da educação: desafios contemporâneos. Petrópolis, RJ: Vozes, 1997.

OLIVEIRA, D. A. Gestão democrática da educação: desafios contemporâneos. Petrópolis, RJ: Vozes, 1997.

PAVAN, R. A municipalização do ensino fundamental: o caso de Santos e Jundiaí. São Paulo, 1998. Dissertação (Mestrado) - PUC/SP.

PONTUAL, P. C. O processo educativo no orçamento participativo: aprendizados dos 
TAVARES. T. M. Gestão municipal da educação, organização...

atores da sociedade civil e do Estado. São Paulo, 2000. Tese (Doutorado) - PUC/SP. ROMANELLI, O. História da Educação no Brasil (1930-1973) .Petrópolis: Vozes, 1978.

ROSAR, M. F. F. Globalização e descentralização: o processo de desconstrução do sistema educacional brasileiro pela via da municipalização. Campinas, 1995. Tese (Doutorado) - Unicamp.

VIEIRA, S. L. Política educacional em tempos de Transição (1985-1995). Brasília: Plano, 2000. 